\title{
What Makes Us So Different from the Apes?
}

\author{
Tony Laying \\ Elmira College
}

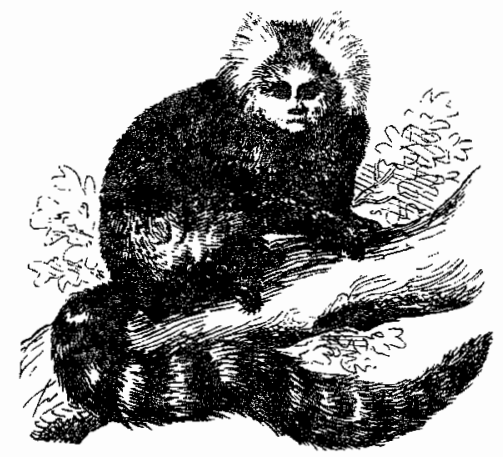

In order to learn more about ourselves, our own species, scholars have long been asking questions about other animals, especially the great apes, since they closely resemble us in so many ways. Gorillas and chimpanzees, and to a lesser extent the gibbons and orangutans, are our closest living relatives; so they have come under much scrutiny in this regard.

Physically, the differences are more apparent than real. The body hair of apes is far more conspicuous than is our own, but we have no fewer hair follicles than they do. Their craniums are proportionately smaller than our own, and their arms are proportionately longer and stronger, but they have the same skeletal structure as we do, bone for bone. Theirs is not as well designed for standing upright, but chimps and gorillas have little difficulty walking in this fashion when they choose to do so.

Of greater significance, most likely, are those differences that have to do with their behavior. For example, they seem capable of surviving only in a certain type of environment, unable to alter their behavior in ways that might enable them to live in other places; and, consequently, they inhabit very few locations. We, on the other hand, thrive in many

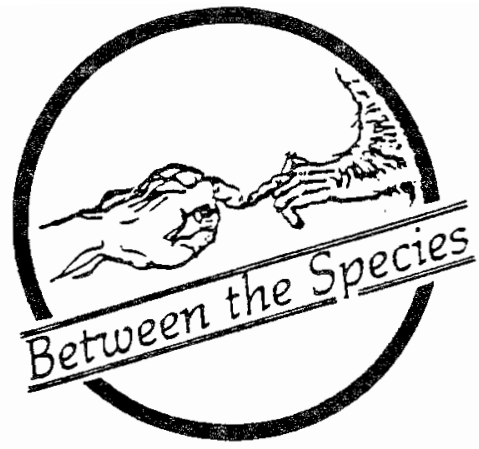

different kinds of environments. And apes do very little to reshape their habitats, while humans extensively alter the territories they occupy. Such differences are illustrated by the wide range of different human cultures and the contrasting uniformity of behavior throughout each ape species.

These differences are more descriptive than explanatory. Such descriptions often pose as explanations of what makes us fundamentally unlike the apes, but to merely point out that there are dissimilarities does not account for these dissimilarities. Answers to the questions "What makes us so different from the apes?" have been around for a long time, but even modern scholars have not yet fully explained these differences. Why, for example, have humans accomplished so much and apes so little? Common sense explanations have always been available, but they are far too simplistic; and as modern scholarship expands, these answers keep changing.

Western scholars at one time posited that since an ape has no soul, unlike humans, this fact alone was largely responsible for the fundamental differences between the destinies of our two species. Our place in the universe, after all, was supposedly guided by an omnipotent supreme being; how could apes possible compete with that? Part of this divine plan, according to Christians, was that humans were created to "rule" the apes, and all other animals of course.

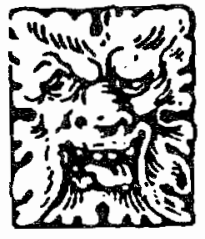


Others in the West have supposed that the fundamental difference between apes and people is mostly a matter of different instincts, that humans have "higher" natural predispositions that clearly distinguish us from the baser tendencies of all animals, apes or otherwise.

Another answer to the question, one that is still popular among intellectuals, is that our rationality sets us apart from these, the most intelligent nonhuman animals. Apes, so goes this theory, cannot reason, or at least they are not capable of truly abstract thought. Our superior brains, it is surmised, not only make us more intelligent but give us mental capabilities that are wholly lacking in apes.

These and other popular beliefs, which most of us might use to explain what makes us so different from the apes, are all deficient to some degree. Even though such attempts to explain what makes us so different from the apes are likely to be viewed by most as both logical and convincing, all are fallacious or at least unsubstantiated in light of what we know about humans and other primates. For example, the belief that the human soul distinguishes "man" from the apes is both ethnocentric and "speciescentric." It is, of course, a common belief among peoples all over the world that we have souls, some tribal populations believing that each of us has multiple souls; and a few societies, the Eskimos for instance, believe that even animals have souls. Now the Eskimos might not know much about apes, but that they attribute souls to the seals and whales that they hunt illustrates the degree to which such beliefs are a reflection of one's culture.

Similarly, to claim that God has a special role in mind for our species entirely contradicts what we now know objectively about religious beliefs in non-Western societies. For example, a number of traditional tribes lacked any belief in a creator god prior to being influenced by Christian missionaries; so to suggest that "God" has imposed a special destiny on us only illustrates the degree to which our thinking is shaped by our cultural biases. And how does one test or confirm these essentially theological premises? The answer, of course, is that one does not, for they are entirely a matter of religious faith.

Then what about instincts? Is it our innate predispositions which separate us most clearly from the apes? When we ask about human nature, rather than about human spirituality, are we at least asking a scientific question? Perhaps, if humans have instincts.
If we do, are some of them uniquely human? It is clearer that we have inborn drives-a sex drive and a hunger drive for example-but these do not make our species special. Instincts are more complicated than unlearned drives, for they involve not only a need to respond to some stimuli but inborn programmed behavior as well. A bird, for example, will build a distinctive style of nest unique to its species even though it has never previously observed nest building or had any other opportunity to learn how to do this kind of consuruction.

A maternal instinct is the one most of ten cited when the subject of human instincts comes up, but those who suggest that women have a natural affinity to protect their young would, presumably, agree that female gorillas are no different in this regard. Do humans have any peculiar instincts, ones that cause them to behave quite differently from the way apes do? It is not at all clear that we do. In fact, it is not certain that humans or apes have any real instincts, at least none that are comparable to those found commonly in animals such as birds.

Westem scholars used to attribute quite a bit of human behavior to instincts. We all supposedly had a self-preservation instinct, and males, at least, had an aggression instinct. Women were considered to be instinctually intuitive and emotional. And just as men and women were instinctually different, races were also predisposed to behave in distinctive ways; darker races were naturally "lazy and childlike, and superstitious." Not surprisingly, white men were consistently presented as having the most desirable instincts, those consistent with the highest values of Western society. Now that social scientists know far more about learning theory, animal behavior, ethnocentrism, racial bigotry, and sexism, we hear far less about human instincts. As our knowledge of human behavior becomes increasingly informed, we refer to less and less of it as being innate.

Well then, what about abstract thought? Sorry. Here too, recent research by primatologists and anthropologists suggests that apes are smarter than we had previously assumed. We have known for years that chimpanzees in captivity were capable of problem solving abstractly; it has been clearly demonstrated that they could conceptually figure out, when sufficiently motivated by anger, that tools absent from their view were applicable to obtaining a meal otherwise out of reach. This certainly required abstract thought. Now, of course, we know that chimpanzees and gorillas have the capacity to communicate symbolically, to learn and 
use language. Washoe the chimp and Koko the gorilla have become celebrities of a sort, appearing in numerous television documentaries demonstrating their ability to "speak" American sign language; and more recently, some chimpanzee students have had success in instructing others of their species in how to utilize this highly abstract form of symbolic communication.

So what can we conclude at this point about the basic differences between apes and humans? As far as religious claims are concerned, there is absolutely no objective evidence that humans have any special spiritual advantage, or that apes lack either a soul or divine guidance. Conclusions about such things are entirely a matter of one's faith in things supernatural. Those who suggest that what is special about humans is our peculiar destiny, that we were ordained to have dominion over all other species, inform us only about their own religious tenets.

Instincts? The continued use of this term in reference to human behavior is little more than a confession of ignorance, something to call the behavior until we come to understand it more fully. Rationality? Abstract thought? We no longer are justified in believing that these are uniquely human attributes, for we now know that chimpanzees use and even make tools for specific purposes, and they are capable of learning and rationally using abstract symbols in the form of complex communication.

So, again, what accounts for the vast differences between ourselves and the apes? Many anthropology textbooks state that only humans have culture, and that is what makes us so special; but we are discovering more and more instances of cultural behavior (patterned behavior that is leamed and shared by members of a social group) among apes and even the less intelligent monkeys. We now know that wild bands of primates can alter their collective, customary learned behavior, and that is what culture is all about.

Just as our uniqueness in the animal world cannot be explained in terms of mysticism or supernaturalism, neither can it be attributed to self-flattering claims to having unique mental abilities, or any other abilities for that matter. Our mental superiority is merely a matter of degree, not a difference of kind. To explain what we have achieved in this world, in contrast to what apes have failed to achieve, we must consider more than our capacity for abstract thought, language, and culture.

Well what is left to consider? If we are to clarify what it is that sets us apart from other animals, I suggest that we concentrate not on presumed or relative differences in capability but, rather, on different needs, for in this regard, the differences may be far more significant. For example, chimpanzees can learn to invent new words and construct original sentences, but they are satisfactorily adapted to their natural environment without doing so. We, on the other hand, must learn to do these things, or we would fail to survive. A human population lacking a language would be unable to sustain itself, for without language we could not adequately share newly derived information and pass it on to subsequent generations. Humans must do this and more; they must discuss past events and plan future activities, they must coordinate their economic behavior and maintain a moral code, and they must reckon their kin and recount their myths. None of these matters are human luxuries; they all are prerequisite to sustaining an orderly society. And human populations which fail to do this are not equipped to survive, especially where they must compete for food with societies that do rely on language.

When the first hominids (primates who walked fully upright) began to develop language and sexual division of labor (lacking among apes), they did so because they had to, not simply because they were able to do so. These early steps in the development of culture gave them a clear advantage over other hominids who failed to invent these things. For example, assigning economic activities by sex, teaching males to hunt and females to collect other foods, not only raised the level of skill employed in these tasks but created an interdependence between men and women which formed the basis of important economic units-families. Through intermarriage between family units, hunting and gathering bands gave structure and cohesion to their composition. And intermarriage between bands enabled practical information gained by one (how to make a new hunting weapon, where to find an additional source of food, etc) to diffuse to the other. Such information sharing, of course, was much facilitated as language continued to evolve.

Populations which lacked language and a division of labor were at a decided disadvantage. They were far less likely to invent tools or plan cooperative economic activities. Apes in the wild make and use some tools, but they are not dependent on those tools, nor is it necessary for them to coordinate their use of tools. Their survival does not necessitate tool use, but humans must invent tools or perish. Our earliest ancestors were rather 
bright, but, more importantly, because they were neither particularly strong nor swift, they were often short of food and frequently preyed upon by other animals. The best defense against starvation and predation that they were able to come up with was culture (learning better methods of coping), and culture worked rather well in this regard.

Humans, far more than apes, desperately need to rely on complex learned and shared behavior. All human societies have clear rules of social conduct, all have religious beliefs, all have a political system and an economic system, all have a complex kinship system, and all have a fully evolved language. If our early ancestors had failed to develop language and culture, long ago they most likely would have become just another extinct species.

So the most fundamental difference between us and the apes is not our capacity to invent tools, language, and a sexual division of labor; it is the fact that apes can get along quite well without these things while humans cannot. Without tools, language, and a sexual division of labor, our early ancestors would not have continued to evolve; and today apes and any surviving hominids would be far more similar than they now are. It is not that gorillas and chimpanzees are incapable of language or a division of labor, it is that humans are unable to survive without these. In short, we need culture; they do not.

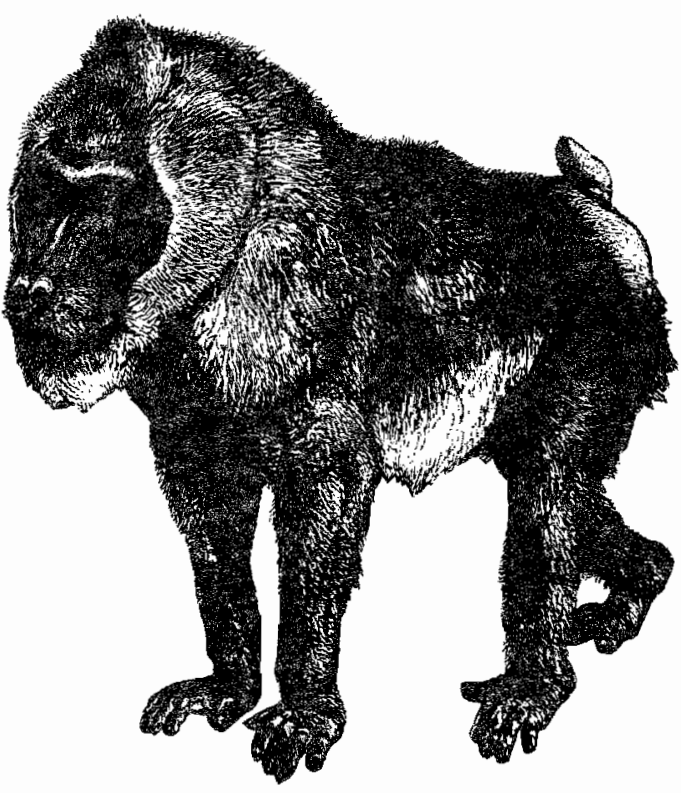

\section{$\mathbb{P} \mathbb{R} \mathbb{E D T} \mathbb{T} \mathbb{R S}$}

Night is almost day.

Trees are red and gold,

the deer are uneasy.

Her silk cat feet move silently.

She has searched a long time.

The mice and squirrels are quick.

She is tired and small.

He drains the last of the beer.

Can is crushed and tossed aside.

Leaves are crisp with frost;

They break easily beneath his boots.

He turns up his collar against morning, and cradles the gun like a child.

A death scent startles her;

Their eyes meet in confusion.

The sound shatters daylight, frightening martens and jays.

Silk feet moving silently, the bobcat falls. 